\title{
Improving bioactive compounds extractability of Amorphophallus paeoniifolius (Dennst.) Nicolson
}

\author{
Anabela S.G. Costa ${ }^{\mathrm{a}}$, João C.M. Barreira ${ }^{\mathrm{a}, \mathrm{b}}$, Adilson Ruas ${ }^{\mathrm{a}}$, Ana F. Vinha ${ }^{\mathrm{a}, \mathrm{c}}$, \\ Filipa B. Pimentel ${ }^{a}$, Rita C. Alves ${ }^{a}, \mathrm{~d}, *$, Isabel C.F.R. Ferreira ${ }^{\mathrm{b}}$, M. Beatriz P.P. Oliveira ${ }^{\mathrm{a}}$ \\ a REQUIMTE, LAQV/Departamento de Ciências Químicas, Faculdade de Farmácia, Universidade do Porto, Rua Jorge Viterbo Ferreira, 228, 4050-313 Porto, \\ Portugal \\ ${ }^{\mathrm{b}}$ Mountain Research Center (CIMO), ESA, Polytechnic Institute of Bragança, Apartado 1172, 5301-855 Bragança, Portugal

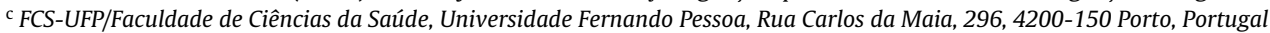 \\ ${ }^{d}$ REQUIMTE, LAQV/Instituto Superior de Engenharia do Porto, Instituto Politécnico do Porto Rua Dr. António Bernardino de Almeida, 431, $4200-072$ Porto, \\ Portugal
}

\section{A R T I C L E I N F O}

\section{Article history:}

Received 24 May 2015

Received in revised form 4 November 2015

Accepted 6 November 2015

Available online 21 November 2015

\section{Keywords:}

Elephant foot yam extracts

Bioactive compounds

Phenolics

Antioxidant activity

\begin{abstract}
A B S T R A C T
Elephant foot yam (Amorphophallus paeoniifolius (Dennst.) Nicolson) is an underground, unbranched deciduous plant that produces a large tubercle (rhizome) with recognized health effects. In this study, the influence of solvent nature (water, water/etanol (1:1) and absolute ethanol) and processing type (fresh, lyophilized and boiled) on the antioxidant activity and bioactive compounds extractability of elephant foot yam was evaluated. Extracts were compared for their contents in total phenolics, flavonoids and tannins. Moreover, their antioxidant capacity was assessed by the ferric reducing antioxidant power (FRAP) and the 2,2-diphenyl-1-picrylhydrazyl radical ( $\left.\mathrm{DPPH}^{\bullet}\right)$ scavenging capacity assays. Phenolics (154 mg $\mathrm{GAE} / \mathrm{L}$ ) and tannins (109 mg GAE/L) were maximized in lyophilized samples extracted with the hydroalcoholic solvent, which attained also the highest FRAP value ( $711 \mathrm{mg} \mathrm{FSE} / \mathrm{L}$ ). In turn, flavonoids reached the highest yields in lyophilized samples ( $95 \mathrm{mg}$ ECE/L) extracted with pure ethanol, as well as the highest $\mathrm{DPPH}^{\bullet}$ scavenging activity. These findings might have practical applications to define the best processing methodology regarding the enhancement of elephant foot yam, either for prompt consumption, as well as to develop food supplements or pharmaceutical related products.
\end{abstract}

(c) 2015 Elsevier B.V. All rights reserved.

\section{Introduction}

Oxidative stress is involved in the etiology of various disorders and diseases, being reasonable to expect beneficial effects of antioxidants in maintaining our health and lowering disease risk (Kris-Etherton et al., 2002; Niki, 2010). Some antioxidants can be produced in the body, but the amounts maybe insufficient, particularly under conditions where production of free radicals is increased. Plants are natural alternative sources of antioxidants that might complement the production of these compounds in living organisms. The antioxidant activity in plants is often correlated to their phenolic contents (Cai et al., 2004; Razali et al., 2012). In addition, there has been a large volume of work aimed

\footnotetext{
* Corresponding author at: REQUIMTE, LAQV/Departamento de Ciências Químicas, Faculdade de Farmácia, Universidade do Porto, Rua Jorge Viterbo Ferreira, 228, 4050313 Porto, Portugal. Fax: +35122018 4958.

E-mail address: rita.c.alves@gmail.com (R.C. Alves).
}

at scientific validation of the efficacy of herbal drugs used in the traditional medicine. Furthermore, the preparation of dietary supplements/nutraceuticals and some pharmaceutical products is increasingly based on the extraction of bioactive compounds from natural matrices (Dai and Mumper, 2010).

Amorphophallus sp. are perennial herbaceous plants, growing in mountain or hilly areas in subtropical regions (Ishrud et al., 2001). Elephant foot yam (Amorphophallus paeoniifolius (Dennst.) Nicolson) is an underground, unbranched plant with large stout mottled leaves. The leaf blade, which sits atop a thick fleshy stem, is divided into hundreds of leaflets, varying among 5 and $12.5 \mathrm{~cm}$ long, with highly ridge ovate or oblong shape. The plant is deciduous, dying back to a large tubercle (rhizome), weighing up to $8 \mathrm{~kg}$ and reaching up to $50 \mathrm{~cm}$ in diameter (Saha et al., 2013; Uprety and Poudel, 2010). Analgesic (Dey et al., 2010), antioxidant (Jayaraman et al., 2010), antibacterial, antifungal (Khan et al., 2008) and cytotoxic (Jayaraman et al., 2007; Khan et al., 2008) activities have been described. Therefore, it is assumable that elephant foot yam might be an important source of bioactive compounds since it is often 
used for the treatment of piles, dyspnea, splenomegaly, and cough (Rastogi and Mehrotra, 1995), being also recognized as analgesic, liver tonic, thermogenic, anthelmintic and diuretic (Arya, 1994).

The effectiveness of bioactive compounds extraction from plants, as well as their corresponding activity, is highly dependent on factors such as different types of solvent, solvent-to-solid ratios, extraction times and temperatures (Pinelo et al., 2005), and specially the solvent polarity (Razali et al., 2012). Accordingly, this work was designed to verify the influence of solvent nature (water, water:ethanol (1:1) and ethanol) and processing type (fresh, lyophilized and boiled) on the antioxidant activity and bioactive compounds extractability of elephant foot yam. Extracts were compared regarding their total phenolics, flavonoids and tannins contents. Moreover, their antioxidant capacity was assessed by two complementary procedures: the ferric reducing antioxidant power (FRAP) method and the 2,2-diphenyl-1-picrylhydrazyl radical (DPPH) scavenging capacity assay. The obtained results might have practical applications when deciding the best processing methodology regarding the enhancement of elephant foot yam extracts, either for prompt consumption as well as to develop food supplements or pharmaceutics related products.

\section{Materials and methods}

\subsection{Reagents and standards}

Gallic acid, epicatechin, Folin-Ciocalteu's phenol reagent, $\mathrm{DPPH}^{\bullet}$ (2,2-diphenyl-1-picrylhydrazyl radical), sodium nitrite, ferric chloride, aluminum chloride, TPTZ (2,4,6-tripyridyl-s-triazine) solution, and ferrous sulfate heptahydrate were all obtained from Sigma-Aldrich (St. Louis, U.S.A). Anhydrous sodium carbonate, sodium hydroxide and absolute ethanol were purchased from Merck (Darmstadt, Germany). Ultrapure water was treated in a Milli-Qwater purification system (Millipore, Bedford, MA, USA) and used to prepare all aqueous solutions.

\subsection{Samples and samples preparation}

Elephant foot yam (A. paeoniifolius (Dennst.) Nicholson was collected from Baucau, a district of East Timor, on the Northern coast in the Eastern part of the country. Voucher specimens were numbered and deposited in the local herbarium. Samples were submitted to different conservation processes (fresh, boiled and lyophilized). For the preparation of the cooked sample, cubes of peeled tubers were boiled at $100^{\circ} \mathrm{C}$ for about $40 \mathrm{~min}$, simulating the domestic cooking process. Afterwards, all visible water was drained out. To obtain lyophilized samples, fine-cut peeled tubers were frozen $\left(-20^{\circ} \mathrm{C}\right)$ and lyophilized (Telstar Cryodos-80 Terrassa, Barcelona). Samples obtained from different conservation processes were ground (Grindomix GM 200, Retsch, Haan, Germany) and used to prepare the extracts described in the next section.

\subsection{Extracts preparation}

Extracts were prepared using three different solvents: (i) ethanol, (ii) water and (iii) ethanol:water 50:50 $(v / v)$. Three individual samples of fresh, boiled and lyophilized foot yam were tested with each solvent. Each sample $(\approx 1 \mathrm{~g})$ was extracted by stirring with $50 \mathrm{ml}$ of the corresponding solvent, at $40^{\circ} \mathrm{C}, 600 \mathrm{rpm}$, for $1 \mathrm{~h}$ and filtered through Whatman No. 4 paper. The residues were then extracted with additional portions of the corresponding solvents. The combined extracts of each solvent were evaporated (ethanol) under reduced pressure (Rotavapor ${ }^{\circledR}$ R-210, Büchi, Flawil, Switzerland) or frozen and lyophilized (water) and re-dissolved in the corresponding extract at an adequate concentration. Stock solutions were stored at $4{ }^{\circ} \mathrm{C}$ for further use; all the assays were carried out in triplicate and the results were expressed as mean values \pm standard deviations (SD).

\subsection{Total phenolics}

Total phenolic contents of diluted extracts $(1: 10 \mathrm{v} / \mathrm{v})$ were determined according to Alves et al. (2010). Briefly, $500 \mu$ l of each extract were mixed with $2.5 \mathrm{ml}$ of the Folin-Ciocalteau reagent (1:10) and $2 \mathrm{ml}$ of a sodium carbonate solution $(7.5 \% \mathrm{~m} / \mathrm{v})$. The mixture was first incubated at $45^{\circ} \mathrm{C}$, during $15 \mathrm{~min}$, followed by $30 \mathrm{~min}$ incubation at room temperature before absorbance readings at $765 \mathrm{~nm}$. Total phenolic contents were calculated from a calibration curve prepared with gallic acid $(10-100 \mathrm{mg} / \mathrm{L} ; r=0.9997)$ and expressed as $\mathrm{mg}$ of gallic acid equivalents (GAE)/L of extract.

\subsection{Total flavonoids}

Total flavonoid contents were determined according to Soares et al. (2013). Aliquots of $1 \mathrm{ml}$ of extract were mixed with $4 \mathrm{ml}$ of distilled water and $300 \mu \mathrm{l}$ of $5 \%$ sodium nitrite. After $5 \mathrm{~min}$ at room temperature, $300 \mu \mathrm{l}$ of $10 \% \mathrm{AlCl}_{3}$ were added, followed (after $1 \mathrm{~min}$ ) by $2 \mathrm{ml}$ of sodium hydroxide $(1 \mathrm{M})$ and $2.4 \mathrm{ml}$ of ultrapure water. The absorbance was recorded at $510 \mathrm{~nm}$. Total flavonoid contents were calculated through a calibration curve of epicatechin $(50-450 \mathrm{mg} / \mathrm{L} ; r=0.9998)$ and expressed as $\mathrm{mg}$ of epicatechin equivalents (ECE)/L of extract.

\subsection{Total tannins}

Total tannins contents were determined according to Shad et al. (2012), with slight modifications. Briefly, $500 \mu l$ of extract (diluted at 1:10 when necessary) were mixed with $2.5 \mathrm{ml}$ of the Folin-Ciocalteu reagent (1:10). After $3 \mathrm{~min}, 2 \mathrm{ml}$ of sodium carbonate $(7.5 \% \mathrm{~m} / \mathrm{v})$ were added. The mixture was kept in the dark for $2 \mathrm{~h}$. Absorbance readings were carried out at $725 \mathrm{~nm}$. Tannins content was calculated from a calibration curve prepared with gallic acid $(10-100 \mathrm{mg} / \mathrm{L} ; r=0.9997)$ and expressed as $\mathrm{mg}$ of gallic acid equivalents (GAE)/L of extract.

\subsection{Antioxidant activity}

\subsubsection{DPPH scavenging activity}

The radical scavenging ability of extracts was analyzed according to the method described by Harini et al. (2012) with some modifications. Briefly, $14 \mu$ l of diluted extract $(1: 10 \mathrm{v} / \mathrm{v})$ were mixed with $186 \mu \mathrm{l}$ of a freshly prepared $\mathrm{DPPH}^{\bullet}$ solution $\left(6.0 \times 10^{-5} \mathrm{~mol} / \mathrm{L}\right.$ in ethanol). The absorbance decrease at 525 min was measured in time intervals of $2 \mathrm{~min}$, in order to observe the reaction kinetics. The reaction endpoint was attained in $40 \mathrm{~min}$. The radical scavenging activity (RSA) was expressed as percentage of inhibition and calculated using the following equation:

$\% \mathrm{RSA}=\frac{A_{\text {control }}-A_{\text {sample }}}{A_{\text {control }}} \times 100$

\subsubsection{Ferric reducing antioxidant power (FRAP) assay}

The FRAP assay was performed according to Benzie and Strain (1996) with slight modifications. Briefly, $90 \mu$ l of diluted extract $(1: 10 v / v)$ were mixed with $270 \mu$ l of distilled water and $2.7 \mathrm{ml}$ of the FRAP solution (containing $0.3 \mathrm{M}$ acetate buffer, $10 \mathrm{mM} \mathrm{TPTZ}$ solution, and $20 \mathrm{mM}$ of ferric chloride). After homogenization, the mixture was kept for $30 \mathrm{~min}$ at $37^{\circ} \mathrm{C}$ protected from light. Absorbance was measured at $595 \mathrm{~nm}$. A calibration curve was prepared with ferrous sulfate $(50-450 \mathrm{mg} / \mathrm{L}, r=0.9998)$ and ferric 

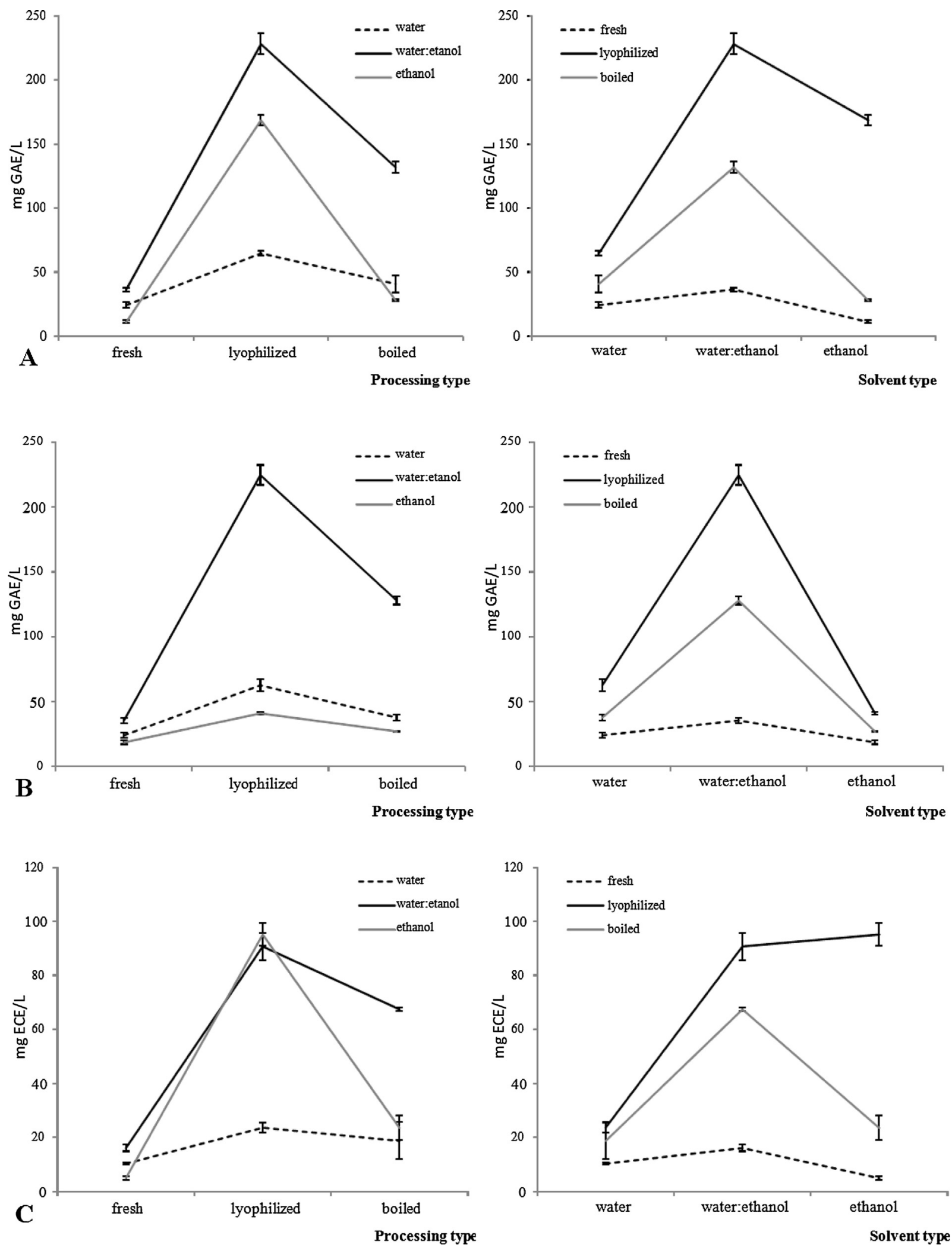

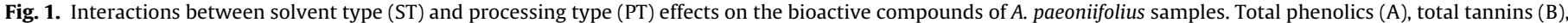
total flavonoids (C). 
Table 1

Bioactive compounds contents obtained for the polar extracts of foot yam submitted to different processing types ${ }^{\mathrm{a}}$.

\begin{tabular}{|c|c|c|c|c|}
\hline & Total phenolics (mg GAE/L) & Total tannins (mg GAE/L) & Total flavonoids (mg ECE/L) & \\
\hline $\begin{array}{l}\text { Solvent } \\
\text { type } \\
\text { (ST) }\end{array}$ & $\begin{array}{l}\text { Water } \\
\text { Water:ethanol }(1: 1) \\
\text { Ethanol } \\
p \text { value }(n=54)\end{array}$ & $\begin{array}{l}43 \pm 17 \\
132 \pm 79 \\
69 \pm 71 \\
<0.001\end{array}$ & $\begin{array}{l}41 \pm 16 \\
129 \pm 78 \\
29 \pm 9 \\
<0.001\end{array}$ & $\begin{array}{l}18 \pm 7 \\
58 \pm 32 \\
41 \pm 39 \\
<0.001\end{array}$ \\
\hline $\begin{array}{l}\text { Processing } \\
\text { type } \\
\text { (PT) }\end{array}$ & $\begin{array}{l}\text { Fresh } \\
\text { Lyophilized } \\
\text { Boiled } \\
p \text { value }(n=54)\end{array}$ & $\begin{array}{l}24 \pm 11 \\
154 \pm 68 \\
67 \pm 47 \\
<0.001\end{array}$ & $\begin{array}{l}26 \pm 7 \\
109 \pm 83 \\
64 \pm 46 \\
<0.001\end{array}$ & $\begin{array}{l}10 \pm 5 \\
70 \pm 33 \\
37 \pm 23 \\
<0.001\end{array}$ \\
\hline $\mathrm{ST} \times \mathrm{PT}$ & $p$ value $(n=162)$ & $<0.001$ & $<0.001$ & $<0.001$ \\
\hline
\end{tabular}

a The results are presented as mean \pm SD. GAE, gallic acid equivalents; ECE, epicatechin equivalents.

reducing antioxidant power was expressed as mg of ferrous sulfate equivalents (FSE)/L of extract.

\subsection{Statistical analysis}

All statistical tests were performed at a 5\% significance level, using SPSS v. 22.0 program (IBM Corp., Armonk, NY, USA). For each processing type (PT) and solvent type (ST), three samples were analyzed, with all the assays being also carried out in triplicate. The results are expressed as mean value \pm standard deviation (SD).

An analysis of variance (ANOVA) with type III sums of squares was performed using the GLM (General Linear Model) procedure of the SPSS software. The dependent variables were analyzed using 2-way ANOVA, with the factors PT and ST. In this case, when a statistically significant interaction $(\mathrm{PT} \times \mathrm{ST})$ is detected, the multiple comparisons classification results cannot be considered, and the two factors should be evaluated simultaneously by the estimated marginal means plots for all levels of each single factor. Alternatively, if no statistical significant interaction is verified, means might be compared using Tukey's honestly significant difference (HSD) multiple comparison test.

Further, a linear discriminant analysis (LDA) was used to compare the effect of the PT and ST on antioxidant activity and extracted bioactive compounds. A stepwise technique, using the Wilks' $\lambda$ method with the usual probabilities of $F$ (3.84 to enter and 2.71 to remove), was applied for variable selection. This procedure uses a combination of forward selection and backward elimination processes, where the inclusion of a new variable is preceded by ensuring that all variables selected previously remain significant (Maroco, 2003; López et al., 2008). With this approach, it is possible to identify the significant variables obtained for each sample. To verify the significance of canonical discriminant functions, the Wilks' $\lambda$ test was applied. A leaving-one-out cross-validation procedure was carried out to assess the model performance.

\section{Results and discussion}

In what regards to antioxidant activity, two assays were performed to evaluate different mechanisms of action: ferric reducing antioxidant power (FRAP), an electron transfer method, which cannot detect compounds that act by radical quenching, but detects compounds with redox potentials lower than $0.7 \mathrm{~V}$ (the redox potential of $\mathrm{Fe}^{3+}$-TPTZ); and the $\mathrm{DPPH}{ }^{\bullet}$ scavenging assay, where the radicals may be neutralized either by direct reduction via electron transfers, or by radical quenching via $\mathrm{H}$ atom transfer (Prior et al., 2005). Also, three groups of compounds were quantified, namely total phenolics, total tannins and total flavonoids. Besides studying the effects of physical variables related with mass transfer kinetics (specifically the solvent type), it was also intended to verify if the way in which the studied matrices were processed exerted a significant effect.

The effects of solvent and processing were evaluated by fixing one of the factors, i.e., the results are presented as the mean value of each ST, including all the PT, and as the mean value of each PT, with the contribution of all ST. Hence, the standard deviation values should not be looked up as a measure of assays repeatability. As it can be concluded from Tables 1 and Table 2, each factor showed a significant effect per si, but the interaction among factors $(\mathrm{ST} \times \mathrm{PT})$ was also a significant $(p<0.001)$ source of variation for all parameters, indicating a strong dependence between the solvent used and the way in which samples were processed. This significant interaction might be easily observed in the estimated marginal means (EMM), where the variation in total phenols, tannins and flavonoids (Fig. 1A-C) among fresh, lyophilized and boiled samples were clearly dependent on the solvent type. For instance, tannin levels are similar for fresh, lyophilized and boiled samples when extracted with water or ethanol, but completely different when extracted with the hydroalcoholic solvent (Fig. 1B). Likewise, while $\mathrm{DPPH}^{\bullet}$ was maximal in boiled samples when using water or water:ethanol, the highest activity in lyophilized samples was reached when the samples were extracted with ethanol

Table 2

Antioxidant properties obtained for the extracts of foot yam submitted to different processing types ${ }^{\mathrm{a}}$.

\begin{tabular}{|c|c|c|c|}
\hline & $\mathrm{DPPH}^{\bullet}$ scavenging activity (\% of inhibition $)^{\mathrm{b}}$ & FRAP assay (mg FSE/L) & \\
\hline $\begin{array}{l}\text { Solvent } \\
\text { type } \\
\text { (ST) }\end{array}$ & $\begin{array}{l}\text { Water } \\
\text { Water:etanol }(1: 1) \\
\text { Ethanol } \\
p \text { value }(n=54)\end{array}$ & $\begin{array}{l}26 \pm 9 \\
57 \pm 21 \\
49 \pm 35 \\
<0.001\end{array}$ & $\begin{array}{l}116 \pm 20 \\
505 \pm 248 \\
287 \pm 273 \\
<0.001\end{array}$ \\
\hline $\begin{array}{l}\text { Processing } \\
\text { type } \\
\text { (PT) }\end{array}$ & $\begin{array}{l}\text { Fresh } \\
\text { Lyophilized } \\
\text { Boiled } \\
p \text { value }(n=54)\end{array}$ & $\begin{array}{l}18 \pm 8 \\
61 \pm 29 \\
53 \pm 18 \\
<0.001\end{array}$ & $\begin{array}{l}97 \pm 53 \\
506 \pm 259 \\
306 \pm 244 \\
<0.001\end{array}$ \\
\hline $\mathrm{ST} \times \mathrm{PT}$ & $p$ value $(n=162)$ & $<0.001$ & $<0.001$ \\
\hline
\end{tabular}

a The results are presented as mean \pm SD. FSE, ferrous sulphate equivalents.

b Diluted extracts (1:10) were tested against a DPPH ${ }^{\bullet}$ solution of $6 \times 10^{-5} \mathrm{~mol} / \mathrm{L}$. 

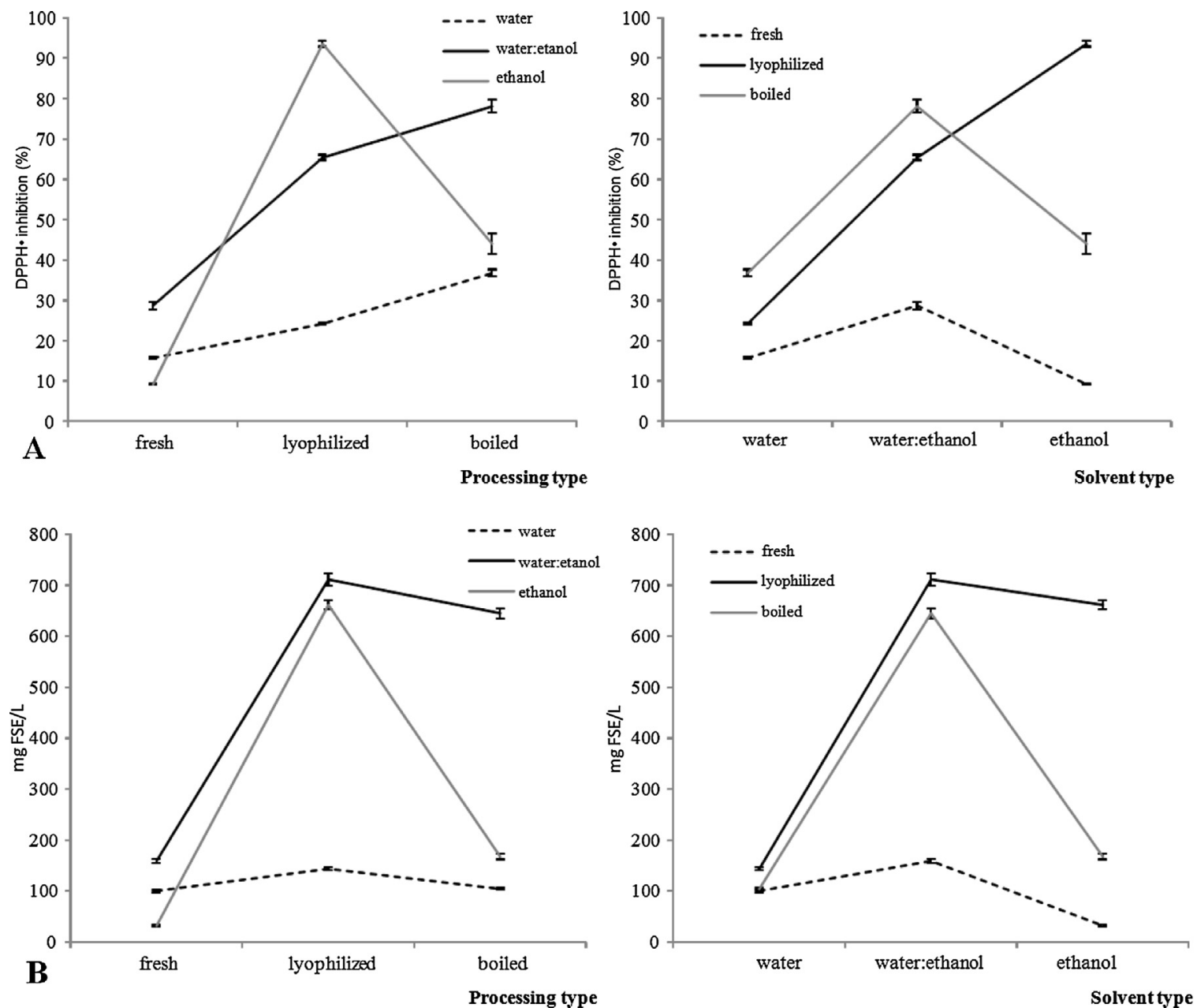

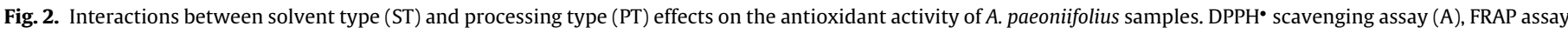
(B).

(Fig. 2A). On the other hand, the ferric reducing power remained nearly the same for fresh, lyophilized and boiled samples when these were extracted with water, but the same samples gave significant differences if extracted with ethanol or the water:ethanol (Fig. 2B). Besides the individual variations, some general conclusions might also be drawn from the EMM: for instance, the highest amounts of total phenolics ( $132 \mathrm{mg} \mathrm{GAE} /$ L extract) and total tannins (129 mg GAE/L extract), as well as the most powerful FRAP (505 mg FSE/L) were achieved with the hydroalcoholic solvent; aqueous extracts revealed the lowest contents in total phenolics $(43 \mathrm{mg}$ $\mathrm{GAE} / \mathrm{L}$ extract), total flavonoids ( $18 \mathrm{mg}$ ECE/L extract) and also the weakest DPPH ${ }^{\bullet}$ scavenging activity (26\%) and FRAP (116 mg FSE/L extract); total tannins content presented the least value $(29 \mathrm{mg}$ $\mathrm{GAE} / \mathrm{L}$ extract) in ethanol extracts. In previous studies, ethanol extracts were reported as having the highest antioxidant efficiency along with the high content of phenolic compounds (Angayarkanni et al., 2010; Jayaprakasha et al., 2008). Herein, the best results were obtained with water:ethanol (1:1), potentially indicating the presence of phenolic acids (which are readily soluble in water) or a high percentage of glycosylated phenolics (it is a well-known fact that glycosylation increases the water solubility of phenolic compounds). Besides the polarity of extraction solvents and the solubility of phenolic compounds, differences might also be explained by changes in the rate of mass transfer (Bi et al., 2009). Regarding the type of processing, lyophilized samples allowed the best results for all assays, except for DPPH ${ }^{\bullet}$ scavenging activity, where it was not possible to differentiate from lyophilized and boiled samples. The detected amounts of bioactive compounds are generally in agreement with previous results in alcoholic extracts of elephant foot yam (Angayarkanni et al., 2010; Nataraj et al., 2009).

Since the antioxidant activity is often correlated with the contents in total phenolics of a determined matrix (Razali et al., 2012), the correlation coefficients among bioactive compounds and antioxidant activity were also calculated. Despite the fact that the DPPH assay is representative of the capacity of test compounds to scavenge free radicals independently from any enzymatic activity, the detected correlations were higher for FRAP assay, especially with total phenolics $\left(y=18.01+3.49 x, R^{2}=0.91\right)$ and total flavonoids $\left(y=3.71+7.69 x, R^{2}=0.95\right)$.

In the following section the results obtained from the conjugated analysis of all parameters are comprehensively analyzed. This approach was followed using linear discriminant analysis in order to have an integrated perspective about the effect of solvent and processing on the antioxidant activity and bioactive compounds amounts. The significant independent variables (evaluated parameters) were selected using the stepwise procedure of the LDA, according to the Wilks' $\lambda$ test. Only variables with a statistically significant classification performance $(p<0.05)$ were kept in the analysis.

Starting with the ST effect, two significant functions were defined (plotted in Fig. 3), which integrated $100.0 \%$ of the observed variance (first, $80.3 \%$; second, $19.7 \%$ ). As it can be observed, the naturally occurring groups (each used solvent) were not completely individualized. However, the classification performance 


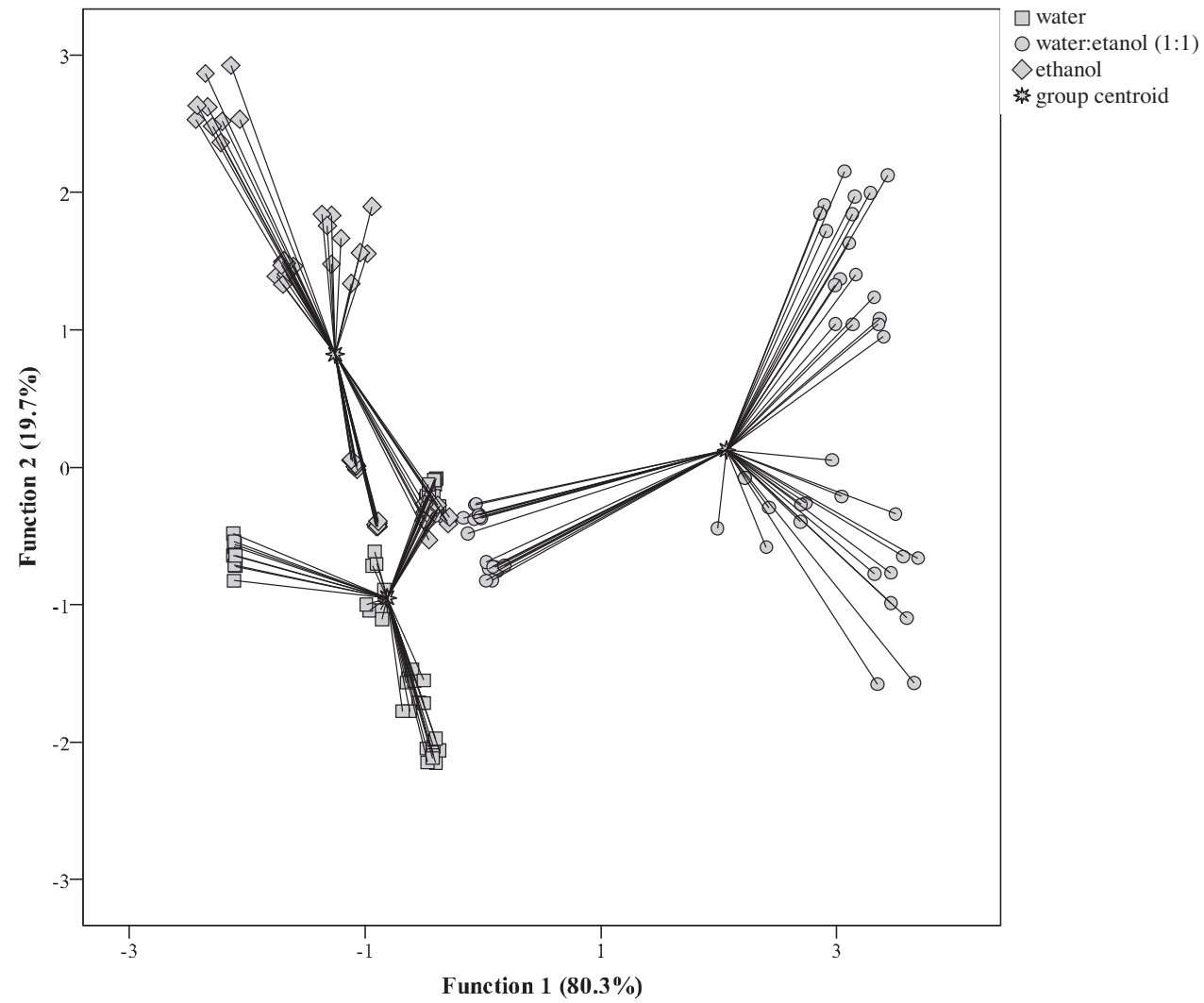

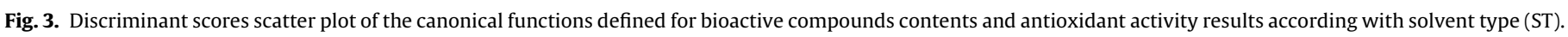

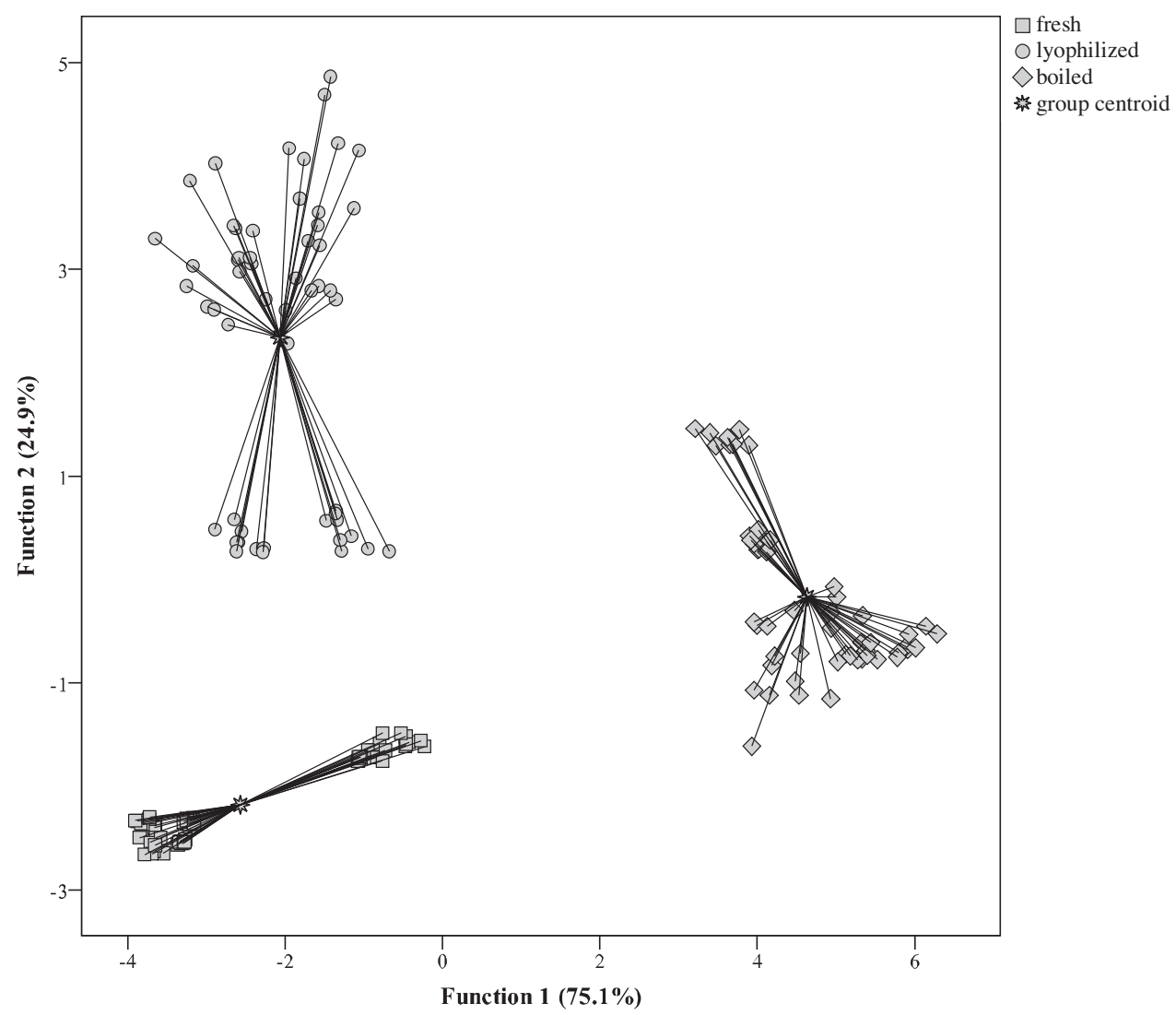

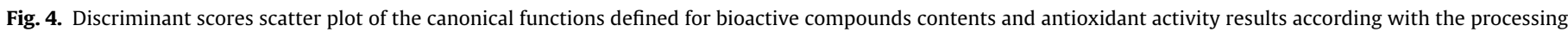
type (PT). 
Table 3

Contingency matrix obtained using LDA based on antioxidant activity and bioactive compounds contents of elephant yam extracts.

\begin{tabular}{llrrrrr}
\hline \multicolumn{2}{l}{ Predicted group membership } & & \multirow{2}{*}{ Total } & Sensitivity (\%) \\
\cline { 1 - 4 } & Water & Water:etanol (1:1) & Ethanol & & \\
\hline Water & 54 & 0 & 0 & 54 & 100 \\
Water:etanol (1:1) & 18 & 36 & 0 & 54 & 67 \\
Ethanol & 18 & 0 & 36 & 54 & 67 \\
Total & 90 & 36 & 36 & 162 & 78 \\
Specificity (\%) & 60 & 100 & 100 & 87 & \\
\hline
\end{tabular}

was satisfactory, resulting in $78 \%$ of correctly classified samples (sensitivity) and $87 \%$ of overall specificity within the leave-one-out cross-validation procedure (Table 3 ). The analysis kept all variables in the final discriminant model, being verified that total tannins and $\mathrm{DPPH}^{\bullet}$ scavenging activity (both higher in hydroalcoholic samples) were the variables with the highest correlation with function 1 and 2 , respectively. The discriminant power proportion of the $n$th function may be estimated by the ratio among its own value and the sum of all discriminant functions values. The canonical discriminant function coefficients allowed obtaining the following model:

$$
\begin{aligned}
D_{1}= & -1.20+0.003 \times \text { phenolics }+0.02 \times \text { tannins }-0.14 \\
& \times \text { flavonoids }-0.002 \times D P P H+0.02 \times F R A P
\end{aligned}
$$

Regarding classification function coefficients, the following functions were obtained:

$$
\begin{aligned}
\text { water }= & -5.08+0.14 \times \text { phenolics }+0.04 \times \text { tannins }-0.32 \\
& \times \text { flavonoids }+0.42 \times D P P H-0.04 \times F R A P
\end{aligned}
$$

water; ethanol $=-9.76+0.06 \times$ phenolics $+0.10 \times \tan$ nins

$$
-0.52 \times \text { flavonoids }+0.34 \times D P P H-0.02 \times F R A P
$$

$$
\text { ethanol }=-4.70-0.01 \times \text { phenolics }+0.04 \times \text { tannins }-0.05
$$$$
\times \text { flavonoids }+0.31 \times D P P H-0.04 \times F R A P
$$

For PT, the discriminant model selected also 2 significant functions (Fig. 4), which included $100.0 \%$ of the observed variance (function 1: $75.1 \%$, function 2: $24.9 \%$ ). In the obtained model, all samples were correctly classified (sensitivity and specificity were obviously $100.0 \%$ ). All variables were included in the final model, with DPPH ${ }^{\bullet}$ scavenging activity and total phenolics (both higher in lyophilized samples) as the variables with the highest correlation with function 1 and 2, respectively.

The canonical discriminant function coefficients allowed obtaining the following model:

$$
\begin{aligned}
D_{1}= & -6.63-0.14 \times \text { phenolics }+0.11 \times \text { tannins }-0.12 \times \text { flavonoids } \\
& +0.36 \times D P P H-0.03 \times \text { FRAP }
\end{aligned}
$$

Regarding classification function coefficients, the following functions were obtained:

fresh $=-10.59-0.40 \times$ phenolics $+0.44 \times$ tannins +0.27

$$
\times \text { flavonoids }+1.66 \times \mathrm{DPPH}-0.16 \times \text { FRAP }
$$

\section{Conclusions}

The statistical interaction among the type of solvent and type of processing was significant in all cases, showing that the effects caused by each selected solvent might depend on the form in which the sample was processed. In addition, the results obtained with LDA indicate that type of processing had a higher influence on the antioxidant activity and bioactive compounds content of the extracts than the extraction solvent. Phenols and tannins concentrations were maximized in hydroalcoholic extracts of lyophilized samples (which presented also the highest FRAP values), while flavonoids reach the highest yields in ethanolic extracts of the lyophilized samples (which also showed the highest DPPH scavenging activity). These findings might have practical applications to define the best processing methodology regarding the enhancement of elephant foot yam, either for prompt consumption as well as to develop food supplements or pharmaceutics related products.

\section{Acknowledgments}

J.C.M. Barreira and R.C. Alves thank to FCT, POPH-QREN and FSE for their grants (SFRH/BD/76019/2011 and SFRH/BPD/68883/2010, respectively). This work received financial support from the European Union (FEDER funds through COMPETE) and National Funds (FCT) through project LAQV UID/QUI/50006/2013. This work also received financial support from the European Union (FEDER funds) under the framework of QREN through Project NORTE-07-0124FEDER-000069.

\section{References}

Alves, R.C., Costa, A.S.G., Jerez, M., Casal, S., Sineiro, J., Núñez, M.J., Oliveira, M.B.P.P., 2010. Antiradical activity, phenolics profile and hydroxymethylfurfural in expresso coffee: influence of technological factors. J. Agric. Food Chem. 58 12221-12229.

Angayarkanni, J., Ramkumar, K.M., Priyadharshini, U., Ravendran, P., 2010. Antioxidant potential of Amorphophallus paeoniifolius in relation to their phenolic content. Pharm. Biol. 48, 659-665.

Arya, V.S., 1994. Indian Medicinal plants-A Compendium of 500 Species. Orient Longman Ltd, Madras, pp. 132-134.

Benzie, I.F.F., Strain, J.J., 1996. The ferric reducing ability of plasma (FRAP) as a measure of antioxidant power: the FRAP assay. Anal. Biochem. 239, 70-76.

Bi, H.M., Zhang, S., Liu, C., Wang, C.Z., 2009. High hydrostatic pressure extraction of salidroside from Rhodiola sachalinensis. J. Food Process Eng. 32, 53-63.

Cai, Y., Luo, Q., Sun, M., Corke, H., 2004. Antioxidant activity and phenolic compounds of 112 traditional Chinese medicinal plants associated with anticancer. Life Sci. 74, 2157-2184.

Dai, J., Mumper, R.J., 2010. Plant phenolics: extraction, analysis and their antioxidant and anticancer properties. Molecules 15, 7313-7352.

Dey, Y.N., De, S., Ghosh, A.K., 2010. Evaluation of analgesic activity of methanolic extract of Amorphophallus paeoniifolius tuber by tail flick and acetic acid-induced writhing response method. Int. J. Pharm. Bio Sci. 1, 662-668.

Harini, R., Sindhu, S., Gurumoorthi, P., Sagadevan, E., Arumugam, P., 2012. Characterization of in vitro antioxidant potential of Azadirachta indica and Abutilon indicum by different assay methods. J. Pharm. Res. 5, 3227-3231.

Ishrud, O., Zahid, M., Viqar, U.-A., Pan, Y.-J., 2001. Isolation and structure analysis of a glucomannan from the seeds of Libian dates. J. Agric. Food Chem. 49, 3772-3774.

Jayaprakasha, G.K., Girennavar, B., Patil, B.S., 2008. Radical scavenging activities of Rio Red grapefruits and Sour orange fruit extracts in different in vitro model systems. Biores. Technol. 99, 4484-4494.

Jayaraman, A., Kunga, M.R., Ulaganathan, P., Poornima, R., 2010. Antioxidant potential of Amorphophallus paeoniifolius in relation to their phenolic content. Pharmac. Biol. 48, 659-665.

Jayaraman, A., Kunga, M.R., Ulaganathan, P., Poornima, R., 2007. Cytotoxic activity of Amorphophallus paeoniifolius tuber extracts in vitro. Am. -Eur. J. Agric. Environ. Sci. 2, 395-398.

Khan, A., Moizer, R., Islam, M.S., 2008. Antibacterial, antifungal and cytotoxic activities of amblyone isolated from Amorphophallus campanulatus. Indian J. Pharmacol. 40, 41-44.

Kris-Etherton, P.M., Hecker, K.D., Bonanome, A., Coval, S.M., Binkoski, A.E., Hilpert, K.F., Griel, A.E., Etherton, T.D., 2002. Bioactive compounds in foods: their role in the prevention of cardiovascular disease and cancer. Am. J. Med. 113, 71S-88S.

López, A., García, P., Garrido, A., 2008. Multivariate characterization of table olives according to their mineral nutrient composition. Food Chem. 106, 369-378. 
Maroco, J., 2003. Análise Estatística, Com Utilização Do SPSS. Edições Sílabo, Lisboa, Portugal.

Nataraj, H.N., Murthy, R.L.N., Setty, D.S.R., 2009. In vitro quantification of flavonoids and phenolic content of suran. Int. J. Chem. Tech. Res. 1, 1063-1067.

Niki, E., 2010. Assessment of antioxidant capacity in vitro and in vivo. Free Rad. Biol. Med. 49, 503-515.

Pinelo, M., Rubilar, M., Jerez, M., Sineiro, J., Núñez, M.J., 2005. Effect of solvent, temperature, and solvent-to-solid ratio on the total phenolic content and antiradical activity of extracts from different components of grape pomace. J. Agric. Food Chem. 53, 2111-2117.

Prior, R.L., Wu, X., Schaich, K., 2005. Standardized methods for the determination of antioxidant capacity and phenolics in foods and dietary supplements. J. Agric. Food Chem. 53, 4290-4302.

Rastogi, R.P., Mehrotra, B.N., 1995. Compendium of Indian Medicinal Plants. Central Drug Research Institute, Lucknow, India, pp. 40-41.
Razali, N., Mat-Junit, S., Abdul-Muthalib, A.F., Subramaniam, S., Abdul-Aziz, A., 2012. Effects of various solvents on the extraction of antioxidant phenolics from the leaves, seeds, veins and skins of Tamarindus indica L. Food Chem. 131, 441-448.

Saha, A., Bose, S., Banerjee, S., 2013. Anti-anxiety activity of Amorphophallus paeoniifolius tuber in mice. J. Pharm. Res. 6, 748-752.

Shad, M.A., Nawaz, H., Rehman, T., Ahmad, H.B., Hussain, M., 2012. Optimization of extraction efficiency of tannins from Cichorium intybus L.: application of response surface methodology. J. Med. Plants Res. 6, 4467-4474.

Soares, M.O., Alves, R.C., Pires, P.C., Oliveira, M.B.P.P., Vinha, A.F., 2013. Angolan Cymbopogon citratus used for therapeutic benefits: nutritional composition and influence of solvents in phytochemicals content and antioxidant activity of leaf extracts. Food Chem. Toxicol. 60, 413-418.

Uprety, Y., Poudel, R.C., 2010. Medicinal Plants of Nepal. Lambert Academic Publishing, Saarbruken, Germany, pp. 124, pp. 